folk/ed. Derg, 2021; 27(3)-107. sayı

DOI: $10.22559 /$ folklor.1692

Araştırma makalesi/Research article

\title{
Iftarlık Gazoz Filmi Örneğinde Sinemada Kültür Koruma Yaklaşımları
}

\section{Cultural Preservation Approaches in the Cinema: The Case Study of the Movie Iftarlık Gazoz}

\section{Aysun Ezgi Yılmaz*}

Öz

Günümüzde dünyanın küresel bir köy haline dönüşmesi, gelişen teknolojiyle birlikte hızlı tüketim çağının yaşanması gibi etmenler; kültürel değerlerin yok olmasına yol açmaktadır. Bireyleri dinlemekten, okumaktan, üretmekten alıkoyan bu çağda; söz ve yazıyı görsellerle harmanlayan zaman açısından tüketim insanının doğasına uygun olan sinemanın, söz konusu kültür erozyonunu önlemede etkili bir araç olduğu düşünülmektedir. Bu bağlamda çalışmaya konu olan, Yüksel Aksu'nun senaristliğini ve yönetmenliğini yaptığı “İftarlık Gazoz” adlı film barındırdığı kültürel unsurlarla birlikte kültürel değerlerin aktarımı ve korunması noktasında örnek teşkil etmektedir. Kültür ve Turizm Bakanlığı tarafından desteklenen filmde yer alan folklorik unsurlar (usta-çırak ilişkisi, türküler, maniler, atasözleri vb.) incelendiğinde söz konusu unsurlara amaçsız bir şekilde yer verilmediği folklorik unsurların bilinçli bir kültür koruma yaklaşımının ürünü olduğu anlaşılmaktadır. Çalışma kapsamında ele alınan film, taşıdığı kültürel

Geliş tarihi (Received): 24.02.2021 - Kabul tarihi (Accepted): 09-07.2021

* * Arş.Gör., Başkent Üniversitesi Fen Edebiyat Fakültesi Türk Dili ve Edebiyatı Bölümü. Research Assistant. Baskent University, Faculty of Arts and Sciences, Department of Turkish Language and Literature aebulbul@baskent.edu.tr. ORCID 0000-0002-6619-0834 
unsurlar göz önünde bulundurularak kültürde tek tipleşmenin önüne geçmek üzere imzalanan Somut Olmayan Kültürel Mirasın Korunması Sözleşmesi ile Kültürel İfade Çeşitliliğinin Korunması ve Geliştirilmesi Sözleşmesi bağlamında değerlendirilmiştir.

Anahtar sözcükler: iftarlık gazoz, sinema, kültür, kültür koruma yaklaşımları

\begin{abstract}
Nowadays, factors, such as the world's being a global village and the fast living of the consumption age together with the developing technology have led to the elimination of cultural values. In this era, which detains individuals from listening to, reading and producing, the cinema is considered to be an effective tool for preventing the present cultural erosion as it is suitable for the consumer's nature by combining the words and texts with the visual elements. In this context, the subject of this research "Iftarlik Gazoz", written and directed by Yüksel Aksu, serves as an example with the cultural elements it contains for their transfer and protection. The movie was supported by Ministry of Culture and Tourism and when the folkloric elements in the movie (masterapprentice relationship, folk songs, mani, proverbs etc.) were examined it can be seen that these elements are not placed irrelevantly; instead, they are aproduct of a conscious culture protection approach. The movie examined here has been evaluated by taking into consideration the cultural elements it has in the context of The Convention for the Safeguarding of the Intangible Cultural Heritage and The Convention on the Protection and Promotion of the Diversity of Cultural Expressions, which were signed for avoiding the standardization in culture.
\end{abstract}

Keywords: İftarlık Gazoz, cinema, culture, cultural preservation approaches

\title{
Extended summary
}

The industrialization wave rising in the 19th century, rapidly developing technology and globalization that influenced societies at a fast pace closed the distances between societies and turned the world into a global village. While elements such as science, technology, etc. developed rapidly during this period, national and local cultures, which create societies and ensure their continuance, faced the danger of "homogenization" as an outcome of globalization. Regarding this issue, United Nations Educational, Scientific and Cultural Organization (UNESCO) treated culture as a whole by elaborating its approach to culture protection and took several steps towards protection and preservation of elements of intangible cultural heritage, along with elements of material culture. Two important treaties adopted by UNESCO for the protection of elements of cultural heritage are Convention for the Safeguarding of the Intangible Cultural Heritage (CSICH), which was adopted in 2003, and Convention on the Protection and Promotion of the Diversity of Cultural Expressions 
(CPPDCE) adopted in 2005. On the other hand, the aspect of practicing the cultural protection, the theory of which was determined by the treaties, is a critical issue. Cultural awareness, which can be obtained through various means such as related courses added to curriculum, thus through in-school education, as well as several out-of-school courses, can also be supported via cultural industries such as cinema, music etc. Especially cinema, which takes a place near the top among spare time activities for today's modern individuals, is an important platform for the protection and preservation of cultural heritage and memory. Within the scope of the study, a cinema film, Iftarlık Gazoz, was tackled in terms of the elements of cultural heritage that it contains, and it was discussed how cultural protection finds a practice area via cinema.

When cinema sector in Turkey from the past to the present is reviewed, it can be seen that cultural elements have been benefitted at every stage. Elements seen in Yeşilçam cinema in the early 1920s (customs, traditions, beliefs etc.) followed by films that draw on the oral culture which incorporates characters from tales, folk stories, and traditional narrative (Keloğlan, Köroğlu etc.) illustrate the use of cultural elements in cinema. Works at later stages that demonstrate cultural change and dilemma centered around rapidly increasing migration from the country to town with the effect of urbanization (Gurbet Kuşları, Gelin etc.) confirm that cultural elements were used in Turkish cinema also in this period. Recently, Karagöz, one of the important elements of traditional theatre, also met with the audience with the cinema film named "Hacivat Karagöz Neden Öldürüldü" and cultural memory has been refreshed.

The Department of Cinema, established in 1977 under the Ministry of Culture, Directorate General of Fine Arts, is the first official institution related to cinema in Turkey. The Directorate General of Cinema, which has continued its existence as the main service unit of the Ministry of Culture and Tourism since 02.11.2011, owns missions such as raising artistic awareness in the public, enabling the transfer of cultural heritage to the next generations, and reinforcing the place of Turkish cinema in the international arena. Among the missions of the institution, "transferring cultural heritage to the next generations" clearly indicates that cinema is seen as a source in the transfer of cultural heritage and qualified as a practice area. CSICH and CPPDCE treaties also approve the use of traditional culture in cinema as a field of cultural industry and point out to the need to protect and promote this sector within the scope of national cultural industries. It is understood that elements of national and traditional culture have started to be used consciously and this situation has been encouraged, with the effect of missions and aims of the Directorate General of Cinema, as well as of the treaties. Iftarlik Gazoz, which was tackled in the present study, is also among cinema films that received financial support from the Directorate General of Cinema under the Ministry of Culture and Tourism.

During the literature review carried out in the research, no study was found that directly discusses how national culture is treated in cinema and how cultural protection occurs in cinema by placing focus on the treaties of culture protection. However, in "Kültür, Edebiyat ve Sinema", which is the third chapter of Nebi Özdemirıs book named "Medya, Kültür ve Sinema", the emphasis that original works can be created with a conscious approach that 
draws on oral and written culture along with the development of Turkish cinema is important in the sense that it draws attention to the relationship between national cinema and culture. The current study, which exemplifies how cultural protection theorized by the treaties is actualized in cinema as a practice area through Iftarlık Gazoz, is important in terms of paving the way for and guiding more comprehensive studies to be carried out in the field.

It is a reasonable approach to benefit from "cinema", which is among popular spare time activities of the modern world and has the power of appealing to every individual young and old alike constituting the society, at the implementation phase of cultural protection theorized by treaties. When Iftarlik Gazoz is considered, it has been determined that in the film lasting about two hours, many elements of cultural heritage such as folk songs, chansonettes, masterapprentice relationship, and traditional practices were given place skillfully and contributions were made to the protection and preservation of cultural heritage, refreshing the cultural memory. It is obvious how importance it is to benefit from elements of national and local culture in national cinema in order to be able to stand up to Hollywood cinema, which is a reflection of the globalization affecting the whole world on the cinema sector, as well as from state support provided for such productions. Even if cinema alone cannot prevent cultural homogenization, producing and supporting works that incorporate elements of local and national culture, as well as introducing them to the public, in this platform with a great influence area, are effective precautions to be taken against the threat of cultural homogenization.

\section{Giriş}

Bir toplumun tarihsel süreç içerisinde ürettiği, gelecek nesillerle organik bağ kurmak üzere aktardığı maddi-manevi unsurlar bütünü olan "kültür", toplumsal kimliğin ortaya konulmasında önemli bir bileşendir. Dinamik bir yap1 olan "kültür"ün korunması ve yaşatılması, toplumların varlıklarını sürdürmeleri noktasında kaçınılmazdır. Kültürel korumanın önemi ve gerekliliği uluslararası platformda atılan adımlar üzerinden de okunmaktadır. Birleşmiş Milletler Eğitim, Bilim ve Kültür Örgütü (UNESCO) kanalıyla 1972'de Doğal ve Kültürel Miras'ın Korunması Sözleşmesiyle başlayan kültür koruma yaklaşımları; 1973'te Yazar Hakları Evrensel Sözleşmesi'ne folklorun korunmasına yönelik protokolün eklenmesi, 1989'da Geleneksel Kültür ve Folklorun Korunması Tavsiye Kararı, 1994 Yaşayan Insan Hazineleri Programı, 1997-98 İnsanlığın Sözlü ve Somut Olmayan Başyapıtlar İlan Programı, 2003 yılında imzalanan Somut Olmayan Kültürel Mirasın Korunması Sözleşmesi (SOKÜM) ve 2006 yılında imzalanan Kültürel Iffadelerin Çeşitliğinin Korunması ve Geliştirilmesi Sözleşmesi (KIFAÇ) gibi çeşitli sözleşme ve kararlar ile sürdürülmektedir.

Ele alınan çalışma kapsamında, "sözlü gelenekler ve anlatımlar, gösteri sanatları, toplumsal uygulamalar; ritüeller, şölenler, doğa ve evrenle ilgili bilgi ve uygulamalar ve el sanatları geleneği” (Oğuz, 2016: 55) ile sınırları çizilen miras alanlarını korumayı ve sürdürmeyi amaçlayan SOKÜM'ün Korunması Sözleşmesi ile somut olmayan kültürel miras 
unsurlarının endüstriyel alandaki kullanımıyla kültürdeki tek tipleşmenin önüne geçme politikası taşıyan KİFAÇ’ın Korunması ve Geliştirilmesi Sözleşmeleri merkeze alınmıştır.

Kültür endüstrisinin bir parçası olan televizyon, radyo gibi araçlarla birlikte elektronik kültür çağının oluşumları arasında yer alan "sinema” yaygın kullanımı ve geniş etki alanı itibariyle tek-tipleşmeye hizmet etme noktasında yadsınamaz bir platformdur. Film sektörü ele alındığında küreselleşmesinin dünya üzerindeki biricik örneği Hollywood sineması söz konusu durumu gözler önüne sermektedir. Nalan Gökdemir ve Ramazan Kurtoğlu, küreselleşme ve dünya film endüstrisini değerlendirdikleri çalışmalarında küreselleşmenin tek tip dünya yaratma hedefinde olduğunu, bu noktada Amerikan'1n tekelinde olan Hollywood filmlerinin de bu dünyadaki tek tip insan modelini yaratmaya hizmet ettiğini ortaya koymaktadır (2015: 51). Hollywood gibi bir akım karşısında ulusal sinema ancak doğru ve bilinçli bir şekilde kullanıldığında yereli ve geleneği koruma noktasında etkili bir araca dönüşebilir. "Sinema"yı küreselleşme bağlamında değerlendiren Burak Bayan da "sinema"nın tüketimi zahmetsiz, iletimi kolay bir anlatım aracı olduğunu" belirtmekte bilgi aktarma, özendirme gibi noktalarda kaynak olarak kullanılmaya başlandığının altını çizmektedir (2007: 215). Edebiyat başta olmak üzere birçok sanat dalından beslenen hem görsel hem anlatıyı bir potada eriterek diğer sanat dallarına oranla daha geniş kitlelere hitap eden böyle bir kaynağın doğurabileceği olumlu ve olumsuz etkiler bu kaynağın nasıl kullanıldığı ile doğrudan ilgilidir. Çalışma kapsamında ele alınan ulusal ve yerel kültür unsurlarından beslenen İftarlık Gazoz filminin gösterime girdiği yıl sinemada tek tipleşmenin kaynağı olarak kabul edilen yüksek meblağlı Hollywood filmlerini geride bırakması sinema gibi etkili bir kaynağın doğru kullanımını örnekler niteliktedir (URL-1).

Toplumdaki bireyleri bir araya getirme gücüne sahip olan sinema, taşıdığ 1 ve yansıttığ1 ortak değerlerle, bireylerde aidiyet duygusunu ve birliktelik ruhunu canlandırabilmektedir. Mikel J. Koven de halkbilim-medya ilişkilerini irdelediği çalışmasında, filmi çağın baskın anlatı türü olarak nitelemekte ayrıca film ve televizyonun hareketli ve elektronik dünyada toplum olma duygusunu kazandırdığını belirtmektedir (2014: 133). Koven'in tespitleri Türk sinema tarihi üzerinden de doğrulanmakta; Türk sinemasında halk bilimsel unsurlardan yararlanıldığı, kitle kültürü karşısında "yerel”i ve "ulusal”’1 koruma ve yaşatma noktasında yapıtlar ortaya koyulduğu görülmektedir. Bu yapıtlar arasında Türk masal geleneğinin temsilcilerinden "Keloğlan"ın konu edildiği "Keloğlan ve Can Kız", "Ben Bir Garip Keloğlanım”, sözlü kültürün halk hikâyesi ayağını yansıtan "Leyla ile Mecnun”, "Kerem ile Aslı", "Ferhat ile Şirin", halk hikâyeciliği ve Âşıklık geleneğini yansıtan "Karacaoğlan” ve "Köroğlu" sayılabilir. Geleneksel tiyatronun mihenk taşını oluşturan Karagöz geleneği de yakın dönem Türk sinemasında yansıtılmıştır. "Hacivat Karagöz Neden Öldürüldü” adını taşıyan filmin eleştirilecek yönleriyle birlikte geleneği yansıtma uğraşının takdire değer olduğunu söyleyen Nebi Özdemir de bu yorumuyla geleneğin sürdürülmesinde sinemanın rolüne dikkat çekmektedir (2012: 278). "Hacivat Karagöz Neden Öldürüldü?” gibi yakın dönemde çekilen ve geleneğin izlerini taşıyan 2008 yapımı "Ulak" adlı film de merkezine sözlü anlatımlardan "masal"ı alarak; masal anlatıcısının özelliklerine, masallarda kullanılan formel sayılara (kırklar, yediler) ve bunlarla birlikte filmde yer alan uygulamalar üzerinden 
Şamanist kültür öğelerine göndermeler yaparak sinemada "yerel” ve "ulusal” kültürün ne şekilde kullanılacağını örneklemektedir.

Türk sinemasında “yerel ve ulusal”’n ele alınıp işlenmesi kadar, popüler kültür ürünü olarak ortaya çıkan yabancı ve uyarlama filmler karşısında halk kültüründen yararlanan yapımların desteklenmesi de önemli bir husustur. Bu yapımların desteklenmesi ve teşvik edilmesi noktasında Kültür ve Turizm Bakanlığı'na bağlı Sinema Genel Müdürlüğü’nün aktif rol aldığı görülmektedir. Kurumun görevlerine bakıldığında özellikle üç madde (b, c, d maddelerinde) sinema kanalıyla yerel ve ulusal kültürü koruma, geliştirme ve yaygınlaştırmaya yönelik hedeflerin varlığı dikkat çekmektedir (URL-2). Sinema Genel Müdürlügü her sene söz konusu amaçlar doğrultusunda birçok filme destek vermektedir. Bu filmlerden biri de 624.033 TL'lik yapım desteği ile çekilen 2016 yapımı "İftarlık Gazoz" adlı filmdir (URL-3). Filmde somut olmayan kültürel miras unsurları ve kültürel ifade çeşitliliğini ortaya koyan örneklerle birlikte bilinçli bir kültür koruma yaklaşımının olduğu filmin yönetmeni ve senaristi Yüksel Aksu'nun verdiği röportaj üzerinden de doğrulanmaktadır. Röportajda kendisine üslubunun en belirgin özelliği sorulduğunda “...yerlilik ve bize ait olanı kullanmak" cevabını veren Aksu; bu açıklamasıyla İftarlık Gazoz'da kültürel unsurları bilinçli olarak tercih ettiğini ve kültürel koruma kaygısı taşıdığını ortaya koymaktadır (URL-4)._

Filmin somut olmayan kültürel mirası ve kültürel ifade çeşitliliğini ne şekilde koruduğuna ilişkin analize geçmeden kısaca filmin konusuna değinilecektir.

\section{Filmin konusu}

Çalışma kapsamında ele alınan "İftarlık Gazoz” yöre olarak Muğla’nın Ula ilçesinde geçmekte, filmin zaman aralığ 1 ise 1970 ile 1980'li yıllar olarak görülmektedir. Film; 1970'li yıllarda küçük bir çocuk olan Adem'in yaz tatilinde el yapımı gazoz üreten Cibar Kemal'in yanında çıraklık yaptığı dönemle birlikte, hapiste ölüm orucunda genç bir mahkum olarak görüldüğü iki ayrı dönemi yansıtmaktadır. Film, Adem'in karne günü gazoz satan Cibar Kemal'den veresiye gazoz almasıyla başlar; karne harçlıklarını alan Adem borcuna sadık kalır ve Cibar Kemal'e ilk firsatta borcunu öder. Dürüstlüğünden ve çalışkanlığından etkilenen Cibar Kemal babasından Adem'i yanına çırak olarak vermesini ister. Baba bu öneriye ilk anda olumlu bakmasa da Adem'in ısrarları üzerine oğlunu çırak olarak Cibar Kemal'in yanına verir. Filmin ağırlıklı kısmı Adem'in çırak olduğu zamanları yansıtırken film siyasi nedenle hapishanede olduğu anlaşılan Adem' in açlık orucunda hayatını kaybettiği sahneyle sona erer (URL-5).

\section{İftarlık gazoz filminin koruma sözleşmeleri bağlamında incelemesi}

Daha öncede belirtildiği üzere, SOKÜM’ün Korunması Sözleşmesinde, korunması amaçlanan beş miras alanı belirlenmiştir. Bu bölümde; SOKÜM'ün Korunması Sözleşmesi’nde belirtilen miras alanları ile KIFAÇ'ın Korunması ve Geliştirilmesi Sözleşmesi kapsamında tek tipleşmeye karşı korunması hedeflenen kültürel ifade çeşitliliğinin bir sinema filmi 
bünyesinde ne şekilde ele alındığg ve işlendiği değerlendirilecektir.

\section{Sözlü anlatımlar ve sözlü gelenekler}

Filmde, SOKÜM'ün Korunması Sözleşmesi bağlamında korunması gereken miras alanlarından sözlü anlatımlar ve geleneklerin yoğun bir biçimde işlendiği görülmektedir. Oğuz'un halk edebiyatı ürünleri ile çerçevesini çizdiği bu alanda; türküler, maniler, halk hikâyeleri gibi halk yaratılarının korunması ve gelecek nesillere aktarılması amaçlanmaktadır (2016: 55). Filmde, filmin çekildiği yöre olan Ege bölgesi türküleriyle (Deniz Üstü Köpürür, Fethiye Çiftetellisi) birlikte farklı yörelerden seçilmiş türkülere (Çekemedim Akça Kızın Göçünü, Cemalim) yer verilmesi; günümüzde küreselleşme ve popüler kültürün etkisiyle oluşmuş (pop, rap, punk vb.) müzikler karşısında ulusal ve yerel kültürün ne şekilde kullanılacağını örneklenmesi bakımından önemlidir.

Filmde kullanılan türkülerden "Cemalim" türküsü ise bu noktada ayrıca incelenmelidir. Türkü, üniversitede siyasi olaylara karıştıktan sonra Ula’ya dönen, tarladaki işçilerle olumlu ilişkiler kurup onları haklarından haberdar eden Hasan'ın (Adem'in babasının çalıştığ tarla sahibinin oğlu) Ankara'dan gelen karşıt siyasi görüşlüler tarafından vurulduğu sahnede kullanılmaktadır:

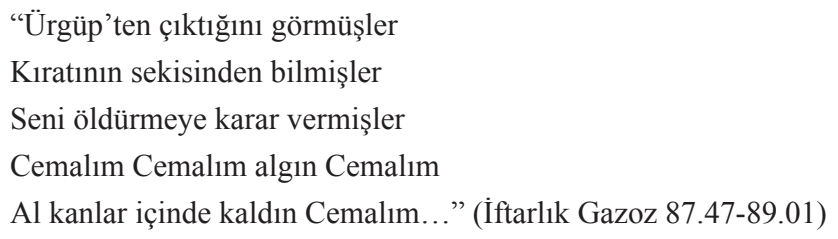

Filmin 87. dakikasında yer verilen bu türkü üzerinden; zengin bir adam olan babasına karşı işçileri örgütleyen ve onları bilinçlendiren Hasan'ın halk anlatı kahramanlarından Köroğlu gibi zenginden alıp fakire veren modern bir halk kahramanı olarak görüldüğü anlaşılmaktadır. Oğuz'un kültürel ifade çeşitliliğini açıklarken (2009: 11) örneklediği Köroğlu türkü içerisinde doğrudan geçmese de onun atı olan Kırat'ın türküde yer alması ve bu türkünün filmde kullanılması kültürel bir gönderme olup kültürel ifade çeşitliliğinin korunmasına ve aktarılmasına katkı sağlamaktadır.

Sözlü anlatımlar ve sözlü gelenekler alanına giren unsurlardan biri de "mani”lerdir. Filmde yer alan manilerin, Adem'in anne ve babasının çalıştığı tütün tarlasında, işçilerin tütün kırdıkları sahnelerde kullanıldığı görülmektedir:

\section{Kadın:}

“Tütün diktim söküldü

Yaprakları döküldü

Eller yarim dedikçe

Benim boynum büküldü” (İftarlık Gazoz 50.40-50.44) 


\section{Erkek:}

"Bahçelerde badılcan

Ben askere yazılcam

Askerden dönünce

Dombul yanaklı giz alcam” (İftarlık Gazoz 50.45-50.50)

\section{Kadın:}

"Köyümüz var hane hane

Haneler tane tane

Bir tarla tütün kırdım

Oldum deli divane" ( İftarlık Gazoz 53.49-53.55)

Geçmişten günümüze varlığını sürdüren manilerin toplumsal hayatta birçok fonksiyonu olduğu bilinmektedir. Mani geleneği ve manilerin işlevlerini ele alan Erman Artun ilgili çalışmasında; manilerin güldürme, eğlendirme, işi kolay kılma, birlik beraberlik ve dayanışma sağlama, sözlü kültürü aktarma, duyguları dişa vurarak rahatlama gibi birçok işlevi olduğuna dikkat çekmektedir (2007: 25). Filmde tütün kırma sahnesinde kullanılan bu manilerin işi kolay kılma, birlik, beraberlik ve dayanışma sağlama gibi işlevleri; uyumlu bir şekilde çalışan ve yaptıkları işten keyif aldığı anlaşılan işçiler üzerinden doğrulanmaktadır. Filmde bu noktada “mani”lerden yararlanılması; geleneğinin korunması ve aktarılmasında atılmış bilinçli bir adım olarak görülmektedir.

Filmde sözlü anlatımlar ve sözlü gelenekler kapsamında değerlendirilebilecek unsurlardan biri de atasözü ve deyimlerdir. Özellikle Cibar Kemal'in çırağı Adem'e mesleğin teknik kısımlarını (satış, pazarlama) aktardığı noktada yer verilen göz hakkı, bal tutan parmă̆ını yalar (İftarlık Gazoz 13-50-14.10) gibi kullanımlar sözlü anlatımları imlerken toplumdaki kültürel ifade çeşitliliğini ortaya koymaktadır.

\section{Gösteri sanatları}

SOKÜM'ün Korunması Sözleşmesi'nde yer alan Gösteri Sanatları; geleneksel tiyatro, halk müziği, halk sporları, halk oyunları ve geleneksel çocuk oyunlarını kapsamaktadır. Özellikle sanayileşme öncesi geleneksel toplumlarda günümüz çocuklarının aksine etrafı bilgisayar, tablet gibi teknolojik cihazlarla çevrilmemiş, varlığını dört duvar arasıyla sınırlamayan mahalle ve sokağa çıkıp hayata karışan çocuklar sık sık bir araya gelerek çeşitli oyunlar oynamaktaydı. Bu oyunlar ilk bakışta çocukların eğlenmesi ve hoşça zaman geçirmesi gibi işlevlerle dikkat çekse de çocukları bir araya getiren oyunlar aynı zamanda sosyalleşme aracıydı. Geleneksel çocuk oyunlarını değerler eğitimi açısından ele alan Yusuf Ziya Sümbüllü ve M. Emin Altınışık da geleneksel çocuk oyunlarının eğlencenin yanında çocuğun nitelik ve nicelik açısından gelişimini destekleyen ve kültürel sürekliliğin sağlayıcısı olan bir faaliyet olarak betimlemektedir (2016: 75). İftarlık Gazoz filminde çocukların oyun 
merkezinde gazoz kapağının yer aldığı görülmektedir. Filmde gazoz kapağı biriktiren, bu konuda birbirleriyle yarış içinde olan ve birbirlerine gazoz kapağı hediye eden çocukların varlığını gösteren üç dört sahne mevcuttur. Öcal Oğuz ve Petek Ersoy’un geleneksel çocuk oyunları üzerine hazırlamış oldukları kitapta (2007: 87) "Kapakla Oynanan Oyunlar" arasında sıraladıkları “Gazoz Kapağı (Çekirdek) Oyunu”na filmde doğrudan bir gönderme olmasa da gazoz kapağı toplayan, biriktiren ve hediye eden çocuklar üzerinden bu oyuna dolaylı olarak bir gönderme söz konusudur. Bu noktada geleneksel bir çocuk oyununa yapılan gönderme ile teknolojinin getirisi olarak bilgisayarlara, dolayısıyla ev sınırlarına hapsedilen çocuklar için alternatif ve daha sağlıklı bir oyun olarak "geleneksel çocuk oyunları"na dönüş fikri hatırlatılmakta aynı zamanda geleneğin korunması ve aktarımına katkı sağlanmaktadır.

\section{Toplumsal uygulamalar, ritüeller ve festivaller}

SOKÜM'ün Korunması Sözleşmesi bağlamında değerlendirilen Toplumsal uygulamalar, ritüel ve festivaller; toplumu oluşturan bireyleri belirli kurallar ve değerlere bağlı kalarak bir araya getiren bireylere aidiyet ruhu ve kimlik kazandıran uygulamaları betimlemektedir. Geçiş dönemleri ve bu dönemlerde yapılan uygulamalar, kutlamalar, milli, dini ve resmi bütün bayramlar, anma günleri, panayırlar, festivaller, dinsel içerikli uygulamalar, ibadet, ayin ve çeşitli ritüeller bu alanda değerlendirilmektedir. Yaptıkları çalışmada toplumsal uygulamaların kendini bir gruba ait hisseden bireyi yalnızlık ve çözümsüzlükten kurtardığını böylece toplumsal hayatın istikrarını ve grubunun sürekliliğini sağladığını belirten Suavi Aydın ve Tayfun Atay toplumsal uygulamaların önemli bir kurum olduğuna dikkat çekmektedir (URL-5).

Filmde toplumsal uygulamalar, ritüeller ve festivaller bağlamında değerlendirilebilecek unsurlardan biri Ramazan bayramının habercisi olan Ramazan ayının başlangıcı ile birlikte toplumda görülen değişiklikler ve uygulamalardır. Filmde Ramazan ayı çerçevesinde; iftar vaktini haber vermek üzere Ramazan topunun atılması, iftarda bir arada yemek üzere kurulan kalabalık iftar sofraları, iftar sonrası erkeklerin hep birlikte teravih namazlarına katılmaları Ramazan ayındaki uygulamalar olarak gösterilmiş bu uygulamaların toplumda dayanışma, birlik ve beraberliğin nasıl perçinlendiği aktarılarak kültürel bellek tazelenmiştir. Yüksel Aksu filmlerinde "din"in yaşamdaki yansımalarını irdeleyen Pervin Soydemir, İftarlık Gazoz'da görülen dini unsurları da detaylı bir şekilde değerlendirmekte; Yüksel Aksu'nun filmleri aracılığıyla günlük hayatın içinde yaşanan dini ve dini uygulamaları yansıtarak kültürel aktarıma katkı sağladığını belirtmektedir (2020: 39).

Filmde, ayrıca Ramazan ayının dinsel pratiği "oruç" yetişkinlerle birlikte çocuklar üzerinden de işlenmektedir. Türk kültüründe çocukların yetişkinler gibi tüm gün oruç tutmadığı ancak oruç tutma alışkanlığı kazanmaları için, isteyen çocuklara yarım günü kapsayan "tekne orucu" için izin verildiği bilinmektedir. Türk Ramazan Kültürü adlı çalışmasında H. Ömer Özden de Ramazanda çocuğunun oruç tutmasının ayrı bir değeri olduğunu, "tekne orucu" altında başlayan oruç tutma sürecinin tam gün oruç tutmaya dönüşmesiyle birlikte bir coşku yaşandığını belirtmektedir (2006: 87). Filmde Adem ile kendinden yaşça büyük olan sınıf 
arkadaşlarından biri arasında geçen diyalog çocuklar arasında "tekne orucu"nun varlığını göstermektedir: Teravih namazı öncesi cami avlusunda Adem'i gören arkadaşı, Adem'in tam gün oruç tuttuğuna inanmaz tam oruç tuttuğunu söyleyen Adem'e “tekne orucudur o, sen yumurcaksın daha ağzın süt kokuyor; sen kim oruç tutmak kim” (30.11-30.29) şeklinde karşılık verir. Çocuklar arasında Ramazan ayı pratiği olarak değerlendirilebilecek "tekne orucu"na filmde yer verilmesi kültürel ifade çeşitliliğini göstermesi bakımından önemlidir.

\section{Usta-çırak ilişkisi}

Geleneksel toplumlarda meslek edinimi, resmi eğitimin ötesinde usta-çırak ilişkisi üzerinden sürdürülmüştür. Türk toplumunda söz konusu süreç uzun bir dönem Ahilik ve sonrasında Lonca teşkilatları aracılığıyla düzenlenmiştir. Geleneğin sürdürülmesi ve aktarılmasında yüzyıllardır önemli bir yapı arz eden usta-çırak ilişkisinde sanayileşme ve modernleşme ile birlikte ciddi bir çözülme yaşanmışsa da günümüzde hala usta-çırak ilişkisiyle varlığını sürdüren meslekler mevcuttur.

SOKÜM'ün Korunması Sözleşmesi'nde korunması gereken miras alanı olarak yer alan El Sanatları Geleneği (Dokumacılık, Bakırcılık, Ebru vb), Gösteri sanatları (Meddahlık geleneği, Karagöz vb.) ve Sözlü anlatımların (Âşıklık geleneği) gelecek kuşaklara aktarılmasında bilindiği üzere "usta-çırak" ilişkisinden yararlanılmaktadır. Gelenekten gelen bilgi ve tecrübenin genç kuşaklara aktarıldığ 1 "usta-çırak" ilişkisi filmde geleneksel bir meslek olarak değerlendirilebilecek "gazozculuk" üzerinden işlenmiş ve usta-çırak arasındaki ilişkisinin derinliği gösterilmiştir. Filmde sosyal bir yapı olarak önemi vurgulanan usta-çırak ilişkisi; daha önce de değinildiği üzere Adem ile el yapımı gazoz yapan Cibar Kemal üzerinden örneklenmektedir. Usta-çırak ilişkisinin başlangıcında oğlunu ustaya teslim eden baba Yörük Osman'ın "Cibar Usta eti senin kemiği benim, sana teslim bana değil gayri” sözlerine Cibar Usta'nın "Ne demek Osman, ben evladım gibi bakarım ona” (İftarlık Gazoz 13.30-13.40) şeklinde verdiği karşılık hem usta-çırak ilişkisinin sınırlarını hem de kültür içerisinde bu kurumun nasıl algılandığını ortaya koyması bakımından dikkat çekicidir.

Türk kültüründe Ahilik Teşkilatını değerlendirdikleri çalışmalarında usta-çırak ilişkisinin sadece teknik eğitimden ibaret olmadığını belirten Gazi Uçkun ve arkadaşları yapılan işin ahlak ilkeleri (dürüstlük, temizlik vb.) temelinde gerçekleştiğini, ayrıca ustanın çırağın ahlaki eğitiminden de sorumlu tutulduğunun altını çizmektedir (Uçkun vd., 2018: 1022). Adem ile ustası Cibar Kemal arasında oluşan usta-çırak ilişkisinde de mesleki eğitim ile birlikte; söz konusu ilişki baba-oğul ilişkisi temeline dayandırılmakta, ayrıca ahlak eğitimi üzerinde de durulmaktadır. Filmde, Adem'in gazoz satarken geçirdiği küçük kaza sonrası ustasının sarf ettiği sözler, bu noktada usta-çırak ilişkisinin derinlikli yapısını bir kez daha göstermektedir:

“Tövbeler olsun yarebbim; yani senin başına bir şey geleceğine benim başıma gelsin. Allah muhafaza sen öleceğine ben öleyim ya! Ya sen bana emanetsin oğlum ya golay mı usta olmanın mesuliyeti; bi tene çocuğu haylayamamış dele. Yarın öbür gün nasıl bakecem babanın yüzüne ya. Çırak almakla evlat sahibi olmak aynı şey; yarın öbür gün ahlaksızlık yapsan kimi ayıplala, beni ayıplala; düzgün ahlaklı adam olsan kimi takdir edele, beni takdi 
edele. Usta buba yarısıdır ya; senin ahlakından canından ben mesulüm. Ben çocuğum olsa adını Adem goyacaktım, babamın adı Adem. Ha çırak Adem ha evladım Adem, aynı!” (İftarlık Gazoz 29.03-29.54).

Sanayileşme ve modernizmle birlikte, günümüzde unutulmaya yüz tutan usta-çırak ilişkisi film boyunca sadece iş ve teknik boyutuyla değil ahlaki ve sosyal boyutlarıyla da işlendiği görülmektedir. Film boyunca usta-çırak ilişkisinin inceliklerin vurgulanması; Âşıklık geleneği, el sanatları, gösteri sanatları gibi usta-çırak ilişkisine dayalı alanlarda bu yapının gerekliliğini ve önemini ortaya koymaktadır.

Filmde el yapımı gazoz/gazozculuk, usta-çırak ilişkisiyle birlikte dönemin değişen tüketim kültürü de gözler önüne serilmektedir. 1960'lı yıllara kadar Türk toplumunda yaygın bir meşrubat olan gazoz, yurtdışı kaynaklı Coca Cola markasının Türkiye pazarına girmesiyle birlikte etkisini kaybetmeye başlamış ilerleyen dönemlerde unutulmaya yüz tutmuştur. “Türkiye'de Gazoz Tarihli” çalışmasında Gazoz ile Coca Cola arasındaki söz konusu rekabete değinen Birol Saygı, Coca Cola Türkiye içecek pazarına girene kadar toplumdaki en yaygın içeceğin gazoz olduğunu belirtmekte Coca Cola ile birlikte gazozun değişen durumunu gözler önüne sermektedir (2017: 64). Filmde de Ula yöresinin el yapımı gazoz üreticisi olan Cibar Kemal' in Coca Cola ile giriştiği söz konusu rekabet açıç̧a yansıtılmıştır. Gazoz'un değerini kaybetmeye başladığını imleyen sahnelerden biri Cibar Kemal'in çırağı Adem'i gazoz satmak için gönderdiği sahnedir. Adem gazozları seyyar bisikletine yükler ve kıraathaneleri gezmeye başlar. Kıraathane sahiplerine gazoz ihtiyacı olup olmadığını sorduğunda "Az önce Cola aldık", "İhtiyaç yok, biz sadece Cola satıyoruz", "Biz sadece Cola satıyoruz" (İftarlık Gazoz: 14.52-15.30) şeklinde benzer yanıtlar alır ve gazoz satışı yapamaz. Bu noktada filmde Gazoz ve Coca Cola kanalıyla işlenen rekabet aslında George Ritzer'in Toplumun McDonaldlaşması tezini Türk toplumu açısından örnekler durumdadır. McDonaldlaşma'yı; hızlı yiyecek restoranlarında geçerli ilkelerin, Amerikan toplumunun diğer kurumları ile birlikte dünyadaki diğer toplumları da egemenliği altına alma süreci (2016: 16-17) şeklinde tanımlayan Ritzer bu teziyle temelde kültürel küreselleşmeden bahsetmektedir. Yerel ve milli kültürleri tek-tipleştiren, kültürel ifade çeşitliliğini yok eden bu durum ulusal değerlerin yitirilmesi noktasında tehdit oluşturmaktadır.

Coca Cola gibi küresel prestije sahip bir tüketim ürünü karşısında etkisini kaybeden gazoz sadece yok olan yerli bir tüketim ürününü imlememekte; aynı zamanda usta-çırak ilişkisiyle geleceğe aktarılan gazozculuk mesleğinin yok oluşunu ve geleneksel çocuk oyunlarından Gazoz Kapağ 1 Oyunun kültürel bellekten silinmesini betimlemektedir. Film'in bir sahnesinde Hasan'ın arkadaşlarına gazoz ısmarladığı sırada kurduğu cümle dikkat çekmektedir: "Yerli Gazoz içmeli, milli burjuvazi desteklenmeli. Memleketin gazozu" (İftarlık Gazoz 59.1459.16) Filmde yer alan bu vurguyla sadece milli burjuvaziyi değil kültürel değerler ve ifade çeşitliliğin de korunmasına katkı sağlanmaktadır

\section{Sonuç}

Dünya üzerindeki kültürlerde küreselleşmeye bağlı olarak meydana gelen tek- 
tipleşmenin önüne geçmek için UNESCO'nun son kırk yıldır sözleşmeler, protokoller ve kararlar aracılığıyla attığı somut adımlar, kültürün korunması ve sürdürülmesinde atılmış ciddi ve mühim adımlardır. Sözleşmelerle teorisi belirlenen bu adımların uygulama aşaması ise kritik bir konudur. Bu bağlamda, KIFAÇ'ın Korunması ve Geliştirilmesi Sözleşmesi'nde belirtildiği üzere sinema, televizyon başta olmak üzere kültür endüstri dallarında $S O K U ̈ M ' u ̈ n$ Korunması Sözleşmesi’nde belirlenen kültürel miras alanlarının kullanılması; tek tipleşme karşısında yerel ve ulusal değerleri öne çıkaracak önemli bir uygulamadır.

Çalışma kapsamında ele alınan İftarlık Gazoz adlı film; usta-çırak ilişkisi, sözlü anlatımlar ve gelenekler, toplumsal ritüeller ve uygulamalar gibi somut olmayan kültürel miras alanları ve kültürel ifade çeşitliliğini ortaya koyan örneklerden yararlanarak kültür endüstrisinin bir kolu olan sinemada yerel ve ulusal değerlerin nasıl aktarılacağını örneklemekte; böylece tektipleşmeye neden olabileceği düşünülen sinemada bilinçli bir koruma politikası izlendiğinde söz konusu olumsuz durumun tersine çevrilebileceğini göstermektedir. İftarlık Gazoz filminin gösterime girdiği yıl gişede rakibi olan Hollywood filmlerini geride bırakması da söz konusu koruma politikasının olumlu sonuçlarını göstermektedir.

Kendini geleneğin karşısında konumlandıran modern dünyada, küresel değerlerin ön plana çıktığı ulusal ve yerel değerlerin ötelendiği inkâr edilemez bir gerçektir. UNESCO çatısı altında imzalanan kültür koruma sözleşmelerinin hayata geçirilmesi ve çeşitli kanallarla (eğitim, sivil toplum kuruluşları, medya vb.) desteklenmesi, korumanın bütüncül olarak gerçekleşmesine olanak tanımaktadır. İletimi kolay ve etkili, farklı grupları (yaş, meslek, cinsiyet vb.) bir araya getirme gücüne sahip, süresi düşünüldüğünde hızlı tüketim kültürüne uygun bir boş zaman etkinliği olan "sinema"nın kültür koruma ve aktarma noktasında kullanılması makul bir girişimdir. İftarlık Gazoz gibi ulusal ve yerel kültür unsurlarından beslenen filmlere sağlanan devlet desteği de bu tür yapımların teşvik edilmesi noktasında alınmış yerinde bir karardır. Sağlanan devlet desteğinin devamı ve süreç içerisinde arttırılması bu yapımların nicelik olarak artışını teşvik edecek bu olumlu adımlar neticesinde tek tipleşmeye hizmet etme potansiyeli taşıyan sinema, tam tersine küreselleşme sonucu ortaya çıkan tek-tipleşmenin önüne geçilmesinde etkili bir araç haline gelecektir. 


\section{Kaynakça}

Artun, E. (2007). Türk halk kültüründe mani söyleme geleneği, manilerin iletişim boyutu ve işlevselliği. IV. Uluslararası Türk Medeniyetlerinde Sözlü Kültür Geleneği (Türk Dünyasında Maniler) Sempozyumu Bildirileri, İzmir: YAZ-AR-BİR ve Fethiye Belediye Başkanlığı1, 21-31.

Buyan, B. (2007). Küreselleşme ve sinema. Beykent Üniversitesi Sosyal Bilimler Dergisi, 1 (1), 214-226.

Gökdemir, N. ve Kurtoğlu, R. (2015). Küreselleşmenin dünya film endüstrisine etkisi ve Hollywood film endüstrisindeki yeni eğilimler. İstanbul Aydın Üniversitesi Dergisi (İAÜD), 19, 27-56.

Koven, M. J. (2014). Halk bilimi çalışmaları, popüler film ve televizyon: Gerekli bir eleştirel araştırma. (G. Y. Halıcı, Çev.) İçinde Uygulamalı halk bilimi. (118-138). Ankara: Geleneksel.

Oğuz, M. Ö. ve Ersoy, P. (2007). Türkiye'de 2004 yılında yaşayan geleneksel çocuk oyunlart. Ankara: Gazi Üniversitesi THBMER.

Oğuz, M. Ö. (2009). Somut olmayan kültürel miras ve kültürel ifade çeşitliliği. Milli Folklor, $82,6-12$.

Oğuz, M. Ö. (2016). Araştırmaların tarihi. İçinde: Türk halk edebiyatı el kitabı (1-60). Ankara: Akçağ

Özdemir, N. (2012). Medya, kültür ve edebiyat. Ankara: Grafiker.

Özden, H. Ö. (2006). Türk ramazan kültürü. A.Ü. Türkiyat Araştırmaları Enstitüsü Dergisi, 30, 83-109.

Ritzer, G. (2016). Toplumun McDonaldlaştırılması -Çă̆daş toplum yaşamının değişen karakteri üzerine bir inceleme- (A. E. Pilgir, Çev.) İstanbul: Ayrıntı.

Sayg1, Y. B. (2017). Türkiye'de gazozun tarihi. Drink Techmarket İçecek ve Teknolojileri Dergisi, Haziran, 114: 60-66.

Soydemir, A. P. (2020). Yüksel Aksu sinemasında yaşamın içindeki din. Ankara: Ürün.

Sümbüllü, Y. Z ve Altınışık, M. E. (2016). Geleneksel çocuk oyunlarının değerler eğitimi açısından önemi. Erzurum Teknik Üniversitesi Sosyal Bilimler Enstitüsü Dergisi, I/2, 73-85.

Uçkun, G., Uçkun, S. ve Üzüm, B. (2018). Türk kültüründe Ahilik: İnsan kaynağ1 yetiştirmedeki yeri ve önemi. TÜRKKÜM 2018. İçinde Uluslararası Türk kültürü ve medeniyeti kongresi bildiri kitab1 (1022-1030).

\section{Elektronik Kaynaklar}

URL-1: Bakanlık destekli filmler gişelerde üst sıralarda. (Erişim Tarihi: 10.11.2020).(https:// basin.ktb.gov.tr/TR-170500/bakanlik-destekli-filmler-giselerde-ust-siralarda.html)

URL-2: Kültür ve Turizm Bakanlığı teşkilât ve görevleri hakkında kanun. (Erişim Tarihi: 
01.10.2020). (https://www.mevzuat.gov.tr/MevzuatMetin/1.5.4848.pdf).

URL-3: Türkiye film sektörü 2016 özet raporu. (Erişim Tarihi: 02.10.2020). (https://film. iksv.org/i/content/1550_1_mob-sektor-raporu-2016.pdf)

URL-4: Özel, B. Yüksel Aksu İftarlık Gazoz bir adem olma hikayesi. Alem. (Erişim 22.09.2020). (https://www.alem.com.tr/Sohbetler/yuksel-aksu-ftarlk-gazoz-br-ademolma-hkayes-663635)

URL-5: Aksu, Y (Yön.) (2016). İftarlık Gazoz. (Erişim Tarihi: 19.09.2020).

(https://www.facbook.com/watch/live/?v=426842561288606\&ref=watch_permalink)

URL-6: Aydın, S. ve Atay, T. "Halk bilimi toplumsal uygulamalar, törenler ve ritüelleri, geçiş törenleri”. (Erişim Tarihi: 15.10.2020).

(https://www.kulturportali.gov.tr/medya/dokuman/dokumandetay/2598)

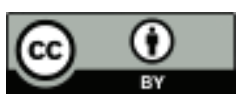

Bu eser Creative Commons Atıf 4.0 Uluslararası Lisansı ile lisanslanmıştır. (This work is licensed under a Creative Commons Attribution 4.0 International License). 